Anal ysi s of tempor al vari abi I i ty of MOD S Leaf Area I ndex ( LAl) product over temper at e for est i n Kor ea

\begin{tabular}{|c|c|}
\hline 著者 & $\begin{array}{l}\text { Ki m Sun- Hwa, Park Ji-Hoon, Wbo Choong- Si k, Lee } \\
\text { Ky u- Sung }\end{array}$ \\
\hline $\begin{array}{l}\text { j our nal or } \\
\text { publ i cat } i \text { on title }\end{array}$ & $\begin{array}{l}\text { Envi r onment al Noni toring In East Asi a ; Renrt e } \\
\text { Sensi ng and For est s }\end{array}$ \\
\hline page $r$ ange & $67-70$ \\
\hline year & 2005-01- 01 \\
\hline URL & ht t p: //hdl . handl e. net /2297/6326 \\
\hline
\end{tabular}




\title{
Analysis of Temporal Variability of MODIS Leaf Area Index (LAI) Product over Temperate Forest in Korea
}

\author{
Sun-Hwa Kim, Ji-Hoon Park, Choong-Sik Woo, and Kyu-Sung Lee \\ Inha University, Department of Geoinformatic Engineering \\ 253 Yonghyun-dong Nam-gu, Incheon 401-751, S.Korea \\ 22032128@inhaian.net
}

\begin{abstract}
DODIS LAI product is very important because it has potential for the monitoring of global scale ecosystem, global change of carbon and water. This study aims to analyze the temporal variability of annual MODIS LAI product using field measured LAI dataset for four vegetation types. The MODIS annual LAI pattern shows the high variety or inaccuracy of LAI during rainy season over South Korea. This phenomenon is caused by high cloud coverage and fails of processing by a radiative transfer model in this rainy season. Annual LAI pattern estimated by a radiative transfer model has least variance of LAI values during this time. In coniferous forest, MODIS annual LAI pattern shows the abnormal decreasing of LAI during nongrowing season comparing with field-measured LAI. This decrease of LAI being an inaccurate phenomenon is caused by rather higher cloud coverage and decreasing of understory plants. MODIS LAI product in deciduous and grass coverage is underestimated by comparing with field-measured LAI. In rice paddy, MODIS LAI shows longer growing season than field measured LAI. For the accurate analysis of temporal MODIS LAI product, it needs considering of vegetation coverage types, cloud coverage, and algorithm types of MODIS LAI.
\end{abstract}

\section{INTRODUCTION}

Since launched the Terra satellite of EOS(Earth Observing System) project, the Moderate Resolution Imaging Spectrometer (MODIS) has delivered global scale biophysical products. Among several biophysical variables, Leaf Area Index (LAI) has been a very important parameters relating with global carbon exchanges, photosynthesis, and evapotranspiration. The MODIS LAI product is expected the large potential of application in biophysics, hydrology, ecosystem, and climate monitoring. For many usages of MODIS LAI dataset, it needs the validation or analysis of MODIS LAI over global and regional scale. Additionally, it also has to be considered time-series analysis of MODIS LAI dataset after 2000. With the generation of MODIS LAI product, the validation of LAI also is processed as EOS project.

MODIS LAI is generated by the Canopy Radiative Transfer (CRT) model or the back-up algorithm. The back-up algorithm is the empirical model using the relationship of the normalized difference vegetation index(NDVI) and LAI. The NDVI is the most commonly used parameter, however, showed the saturation phenomenon in high LAI value [1][2].

The MODIS LAI product is validated by largely two parts. One is the validation with the field-measured LAI dataset or a reference LAI map generated from higher resolution optical images. Several studies generate the reference LAI map using Landsat ETM+ image, and compare with MODIS LAI and reference LAI map [3][4][5]. The other is the validation by MODIS LAI algorithm itself. The radiative transfer model is affected by the spatial resolutioin of input reflectance image, the accuracy of a land cover map being input data of RT model, and cloud coverage [6]. In case of time-series analysis of MODIS LAI dataset, cloud coverage is the important factor and has large effects on the quality of MODIS LAI product [7]

In this study, we attempted to analyze the temporal variability of time-series MODIS LAI dataset. We used the field-surveyed LAI dataset for various vegetation types during one year. Comparing with field LAI dataset, we analyze the temporal variability of the MODIS LAI on temperate forest of South Korea.

\section{STUDY SITE AND DATASET USED}

The study site of this study is South Korea located at Korean Peninsula. It is about $9,350,000$ ha area and about $66.1 \%$ of total land cover is the forest area, coniferous and deciduous forest are composed each about $42 \%$ and $26 \%$ of total forest area. Crop area of South Korea is about $1,860,000$ ha area. Climate of South Korea is the warm temperate region, annual mean temperature ranged from $3.7^{\circ} \mathrm{C}$ to $14.7^{\circ} \mathrm{C}$ [8]. Annual mean precipitation is $1283 \mathrm{~mm}$, two third of total precipitation comes at summer rainy season.

For this study, we use total 46 MODIS LAI products in 2003. This MODIS LAI dataset is composed of total four image layers of LAI, fAPAR, two Quality Control variables. We use only LAI and Quality control image layer. Each properties of two dataset are as Table I. 
TABLE I

SPECIFICS OF MODIS LAI PRODUCTS USED IN THIS STUDY

\begin{tabular}{|c|c|}
\hline Items & MODIS LAI product \\
\hline Collection version & Collection 4 \\
\hline Date & $2004.01 .01-2004.12 .27$ \\
\hline \# of Scenes & Total 46 scenes \\
\hline Spatial resolution & $1 \mathrm{~km}^{*} 1 \mathrm{~km}$ \\
\hline Coordinate system & Sinusoidal Coordinate system \\
\hline Composition & 8-day composition \\
\hline & LAI \\
Layers & FPAR \\
& FPARLAI_QC \\
& FparExtra_QC \\
\hline
\end{tabular}

Additionally, we used MODIS Land cover Product as the input dataset of MODIS LAI product for analysis of temporal variation of LAI for various vegetation cover types.

\section{FIELD-MEASURMENTS OF LAI}

Although the accurate measurement of LAI is crucial to analyze the MODIS LAI product, it is often difficult to obtain reliable ground-truth of LAI. The field-measurement of LAI can be divided into two major approaches: direct and indirect methods [9][10]. The direct method includes destructive harvest, litterfall collection, and application of allometric equations. In recent years, several optical devices become available for the indirect measurement of LAI. The basic concept of optical LAI measurement is to invert a radiation model that describes the amount of light penetrating tree canopy as a function of leaf area and distribution.

In this study, we used the Li-Cor LAI 2000 plant canopy analyzer, which is a commercial instruct to indirectly measure LAI. This device estimates LAI by measuring light transmittance under the forest canopy like as other optical devices. For coniferous and deciduous forest, we conduct total ten time series measurements of LAI in 2003 as shown in Table II. The date of field LAI measurement for rice paddy and grass is different from date of MODIS LAI production. However, rice paddy and grass show very similar annual LAI pattern over years. Date and measurement method of LAI are specified as Table II.

TABLE II

SPECIFICS OF FIELD MEASURED LAI FOR FOUR VEGETATION TYPES

\begin{tabular}{|c|c|c|c|}
\hline Cover types & Date & Method & Location \\
\hline Coniferous & \multirow{2}{*}{$\begin{array}{l}\text { April,2004 } \\
\text { March,2005. }\end{array}$} & \multirow{2}{*}{ LAI-2000 } & \multirow{2}{*}{ Mt. Key-Yang } \\
\hline Deciduous & & & \\
\hline $\begin{array}{c}\text { Paddy } \\
\text { [11] }\end{array}$ & May Oct.,1996 & Li-3100 & Suwon \\
\hline $\begin{array}{c}\text { Grass } \\
{[12]}\end{array}$ & $\begin{array}{c}\text { July Oct. } \\
1985 .\end{array}$ & $\begin{array}{c}\text { Destructive } \\
\text { harvest }\end{array}$ & Suwon \\
\hline
\end{tabular}

\section{ANALYSIS METHOD OF TEMPORAL VARIABILITY OF MODIS LAI}

In four layers of MODIS LAI/FPAR product, LAI and quality control layer are selected and reprojected for the UTM coordinate system. For temporal analysis of MODIS LAI product, we use total 46 products of 8-day composite in 2003. We extract the annual MODIS mean LAI value of each 46 MODIS products of South Korea. Annual pattern of MODIS LAI value is analyzed by using field-measured LAI in 2003.

MODIS LAI value is dependent on the quality factors of production (cloudy state, total quality degree, and algorithm types estimated LAI). For the accurate analysis of MODIS annual LAI, it needs considering of several quality factors. Therefore, these annual LAI patterns of each quality factors are compared with total annual mean LAI value in this study as shown in Fig. 1.

MODIS LAI value is also affected by vegetation cover types. For analysis of MODIS LAI in various vegetation cover types, we use the MODIS Land cover product (type 3) as the input dataset of MODIS LAI product. After MODIS annual LAI pattern in needleaf forest, broadleaf forest, grass, and crop are constructed, these MODIS annual LAI patterns are compared with time-series field-measured LAI at four vegetation cover types. Fig. 1 showed the flow chart for temporal analysis of MODIS LAI.

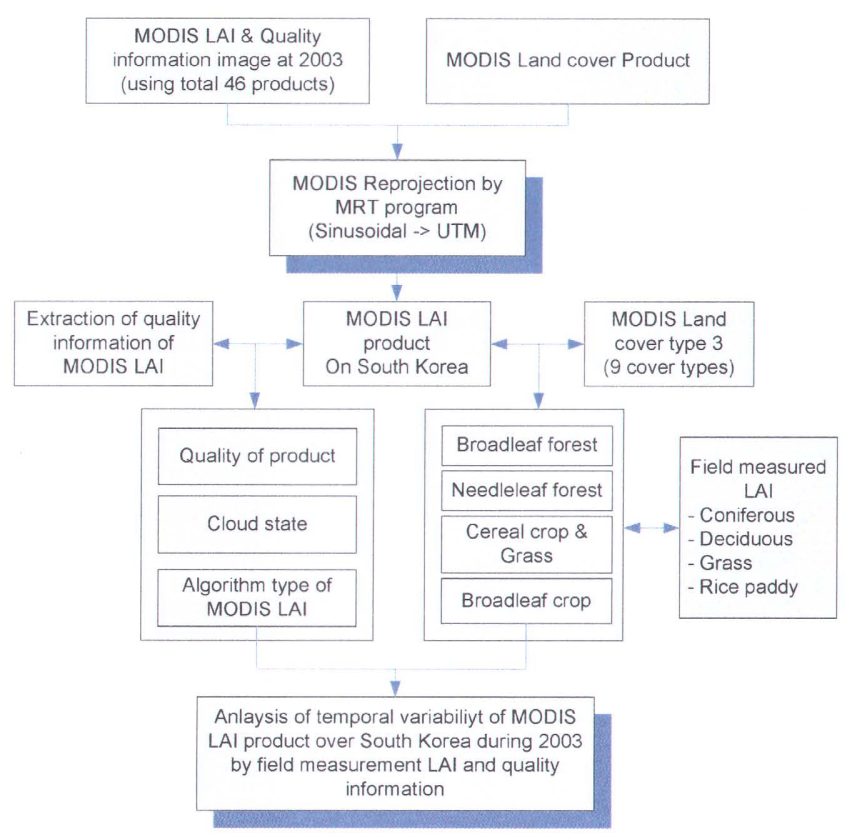

Figure 1. Flow chart for analysis of temporal variability of MODIS LAI using field measured LAI. 


\section{RESULTS}

\section{A. Analysis of quality of the MODIS LAI product}

Mean MODIS LAI is increasing from April, 2003, the highest LAI value is about 5.0 during growing season. As shown in Fig. 2, there are some large variations of MODIS mean LAI value in growing season. Generally, LAI increases in growing season without the large changes of LAI value. The decrease of mean LAI value in growing season is caused by heavy cloud of rainy season from late June to early August. This phenomenon is shown at Fig. 2, cloud coverage is higher at rainy season. Because the high cloud coverage causes the fail to run of the radiation transfer model, back-up model is applied mainly during rainy season as seen in Fig. 2. The high cloud coverage and usages of the backup model causes the abnormal phenomenon of MODIS LAI in rainy season. Comparing with the MODIS LAI value estimated by back-up model, the MODIS mean LAI value estimated by radiative transfer model has lower variation and is not affected by cloud.

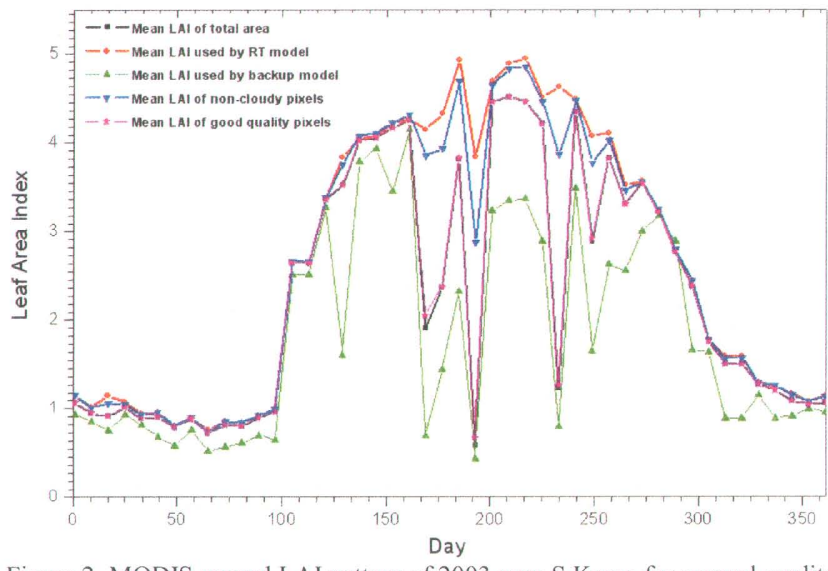

Figure 2. MODIS annual LAI pattern of 2003 over S.Korea for several quality variables.

\section{B. Analysis result of the MODIS LAI with field-measured LAI in four vegetation cover types}

The annual patterns of MODIS LAI of four vegetation cover types are showed at Fig. 3, 4, 5 and 6. At Fig. 3, the mean MODIS LAI of coniferous forest during non-growing season is decreased as like the deciduous forest. This is the abnormal temporal phenomenon. Because coniferous forest is mainly composed with species of evergreen leaf and has no leaf-off season, annual mean LAI value is constant and has no largely decreasing of LAI value over one year.

Comparing with the field-measured LAI, the MODIS LAI in the coniferous forest is very lower. The abnormal pattern of MODIS LAI may be caused by relative high cloud coverage and frequent usages of back-up model in non-growing season. Another reason may be the decreasing of the understory plants, this means that MODIS LAI in coniferous forest are affected by LAI of the understory plants.

At the deciduous forest, the MODIS mean LAI is similar as field measured LAI in non-growing season. By contrast with
MODIS LAI in non-growing season, the MODIS mean LAI is overestimated comparing with the field-measure LAI in the growing season. The total annual pattern of MODIS LAI is similar as temporal pattern of field-measured LAI.

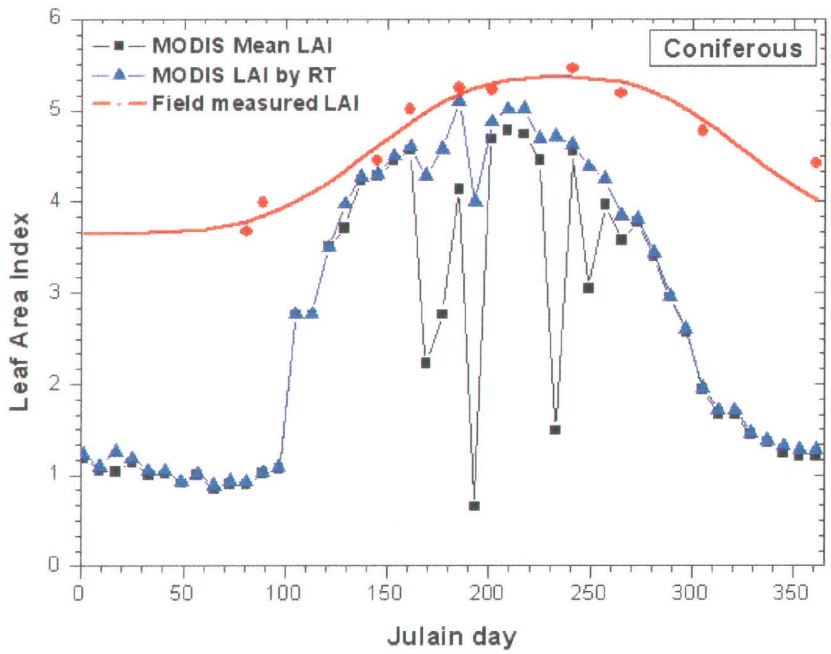

Figure 3. MODIS annual LAI pattern and field measured LAI of 2003 over coniferous forest of South Korea.

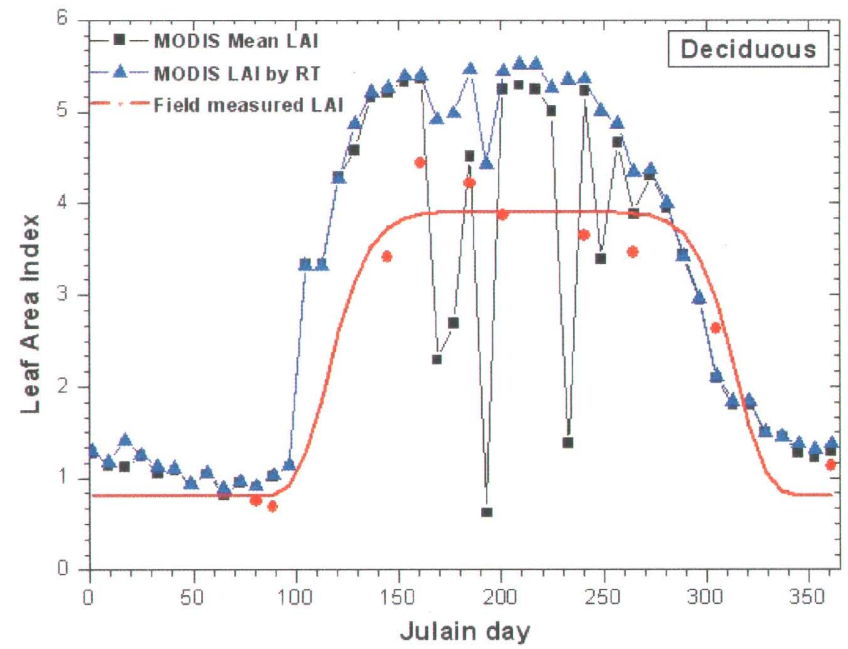

Figure 4. MODIS annual LAI pattern and field measured LAI of 2003 over deciduous forest of South Korea.

Rice paddy of South Korea is seeding from late April to early May, and the harvesting of rice paddy is done at September or October. Generally the growing period of rice paddy was is 150 days. As seen in Fig. 5, the field-measured annual LAI pattern is shown well the growing pattern of rice, but MODIS annual mean LAI showed longer growing period of rice.

The grass for field-measured LAI is planted artificially, grown from 26 May to 30 September, 1985. The grass can't represent well the variance of the natural grass and the growing period of this grass is very artificial for specific projective. However the field-measured LAI pattern of this 
grass showed the typical temporal pattern of grass that LAI is constant after highest growing season as shown in Fig. 6. By contrast with the field-measured LAI in the grass, the MODIS annual LAI pattern has longer growing period. Additionally, the MODIS LAI value has shown temporal variety during growing season, this phenomenon is caused by high cloud coverage.

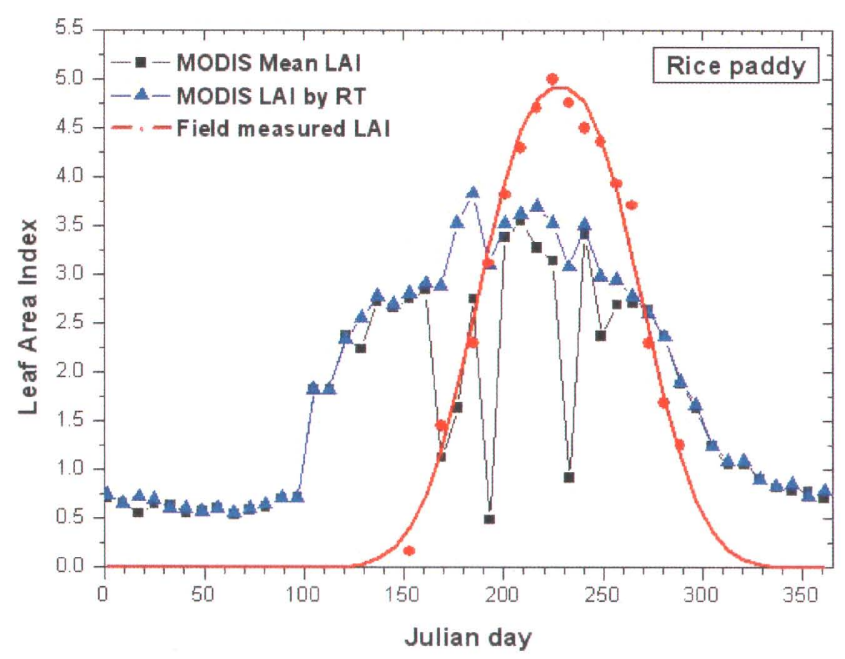

Figure 5. MODIS annual LAI pattern of 2003 and field measured LAI over rice paddy of South Korea.

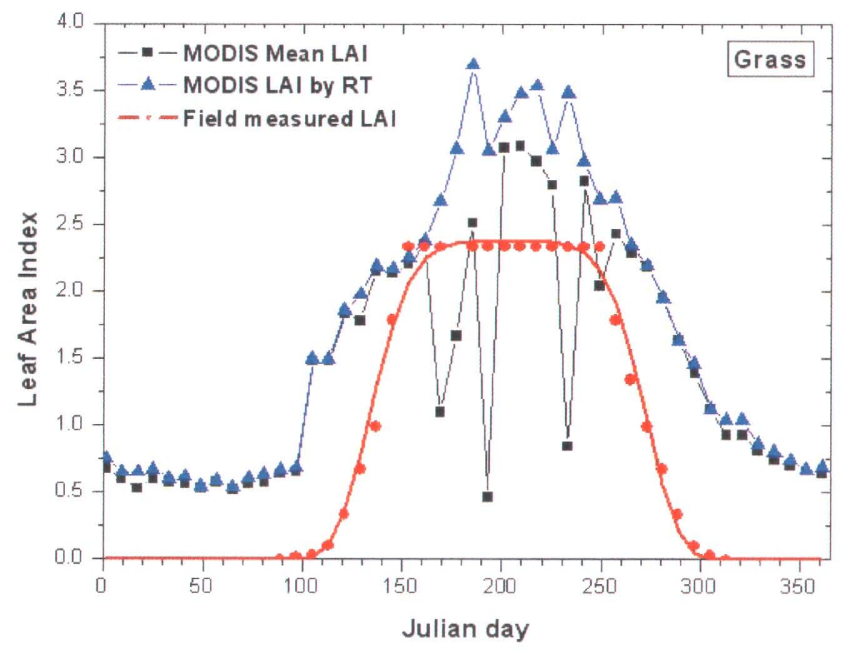

Figure 6. MODIS annual LAI pattern of 2003 and field measured LAI over grass of South Korea.

\section{CONCLUSIONS}

Global scale MODIS LAI product has delivered from 2000, this study is analyzed the temporal variety of MODIS LAI product during 2003. The results of this study show that the MODIS LAI product is affected by the vegetation cover types, cloud coverage, and algorithm types of MODIS LAI product.
Below contents show the temporal variability of MODIS LAI product and the analysis results of the MODIS LAI product with field-measured LAI.

- The temporal MODIS LAI in rainy period shows the higher variability of LAI because of higher cloud coverage and higher percentage of pixels estimated by back-up model.

- MODIS annual LAI pattern estimated by radiative transfer model is less various than the back-up model. Therefore, it has to consider the used algorithm types of MODIS LAI and cloud coverage information before the temporal analysis of MODIS LAI.

- MODIS LAI pattern of the coniferous forest shows the decreasing pattern in non-growing season, this is inaccurate comparing with field measured LAI. The inaccuracy may be caused by higher cloud coverage and the decrease of the understory plants. In further study, more accurate reason of this phenomenon will be fine out.

- MODIS annual LAI of the deciduous forest and grass are overestimated by comparing with field measured LAI during growing season. In the rice paddy, MODIS annual LAI pattern shows longer growing period than the field-measured LAI.

- Further, it needs the developing of the temporal function of field-measured LAI for accurate validation of MODIS LAI product and needs the identifying of the reason about the temporal variation or the inaccuracy of MODIS LAI product.

\section{REFERENCES}

[1] J.M. Chen and J. Cihlar, "Retrieving leaf area index of Boreal conifer forests using Landsat TM images," Remote Sensing of Environment, vol. 55 , pp. $153-162,1996$

[2] T.N. Carlson and D.A. Reley, "On the relationship between NDVI, Fractional Vegetation Cover, and Leaf Area Index," Remote Sensing of Environment, vol.62, pp.241-252, 1997.

[3] W.B. Cohen, T.K. Maierpserger, S.T. Gower, and D.P. Turner, "An improved strategy for regression of biophysical variables and Landsat ETM+ data," Remote Sensing of Enviroment, vol. 84, pp.561-571,2003.

[4] Y. Tian et al., "Multiscale analysis and validation of the MODIS LAI product I. Uncertainty assessment," Remote Sensing of Evironment, vol.83, pp. 414-430, 2002

[5] S.H. Kim and K.S. Lee, "Local validation of MODIS global Leaf Area Index(LAI) product over temperate forest," Korean Journal of Remote Sensing, vol. 19, pp.1-9, 2003.

[6] Y. Tian, Y. Zhang, and Y. Knyazikhin, " Prototypingof MODIS LAI and fAPAR algorithm with LASUR and Landsat data," IEEE Transactions on Geoscience and Remote Sensing, vol. 38, pp.2387-2400, 2000.

[7] W. Yang et al., "Analysis of Global MODIS Leaf Area Index and Fraction Absorbed PAR time series data from February 2000 to December 2003," Journal of Geophysics research, submitted for publication.

[8] Y.J. Yim and S.D. Kim, " Climate-diagram map of Korea," Korean Journal of Ecology, vol. 6, pp. 261-272, 1983

[9] J.M. Chen, P.M. Rich, S.T. Gower, J.M. Norman, and S. Plummer, "Leaf area index of boreal forests:Theory, techniques, and measurements," Journal of Geophysical Research, vol.102,pp.29429-29443, 1997.

[10] S.T. Gower, C.J. Kucharik, J.M. Norman, “ Direct and indirect estimation of Leaf Area Index, fAPAR, and Net Primary Production of terrestrial ecosystems," Remote Sensing of Environment, vol. 70, pp. 29-51, 1999.

[11] S.Y. Hong, "Analysis on rice growing information and estimation of paddy field area by using remotely sensing data," Kyungpook National University, 1998.

[12] H.S. Jin and J.Huh, " A Study on the Dry Matter Production and Growth Analysis of Zoysia japonica," Korean J.Ecol. vol.9(3), pp.161-184, 1986. 